\title{
Endoscopic Septoplasty Versus Conventional Septoplasty: Study of 60 Cases
}

\author{
Islam MA ${ }^{1}$, Mohammad T2*, Mamoon TB ${ }^{3}$, Milki FU ${ }^{4}$, Lutfur ASM ${ }^{5}$, Chowdhury $\mathrm{NH}^{6}$ and Hossain $\mathrm{M}^{7}$ \\ ${ }^{1}$ Professor and Head, Otolaryngology-Head \& Neck Surgery, Bangladesh Medical College Hospital, Bangladesh \\ ${ }^{2}$ Assistant Registrar, ENT, Bangladesh Medical College Hospital, Bangladesh \\ ${ }^{3}$ Consultant ENT, Bangladesh Medical College Hospital, Bangladesh \\ ${ }^{4}$ Assistant Registrar ENT, Bangladesh Medical College Hospital, Bangladesh \\ ${ }^{5}$ Resident Surgeon, Bangladesh Medical College Hospital, Bangladesh \\ ${ }^{6}$ Assistant Professor, ENT, Bangladesh Medical College Hospital, Bangladesh \\ ${ }^{7}$ Professor and Head, Otolaryngology-Head \& Neck Surgery, Ibrahim Medical College \& BIRDEM Hospital, Bangladesh
}

*Corresponding author: Tareq Mohammed, Assistant Registrar, ENT, Bangladesh

Medical College Hospital, Bangladesh.

Received Date: September 24, 2020

Published Date: October 07, 2020

\section{Abstract}

Objective: Traditional surgeries of the nasal septum improve the nasal airway but recent development and advancement of the knowledge about endoscope has changed the treatment modality significantly. Endoscopic approach under good Illumination and magnification lessens the chance of injuring the vital structures and hence lessen the chance of complication. This study is done to compare the conventional method with endoscopic method.

Method: Total 60 cases of deviated nasal septum, refractory to conservative medical treatment were randomly selected \&divided into 2 equal groups. 30 patients underwent endoscopic Septoplasty and 30 patients by conventional method. All of them were followed up for 6 months.

Results: The age distribution was ranging from 16 to 60 . Out of them 28 patients (93.33\%) of endoscopic group and 25 patients (83.33\%) on conventional group were relieved from symptom. In endoscopic Septoplasty group, along with Septoplasty functional endoscopic sinus surgery was carried out in 4 patients $(13.33 \%)$. In conventional group 4 patients $(16.67 \%)$ had intra and postoperative complications like excessive hemorrhage and septal perforation etc.7 patients (23.3\%) of conventional Septoplasty group presented with recurrence or persistence of symptom within 6 months of surgery.

Conclusion: Though conventional Septoplasty is widely practiced by most ENT surgeons till now, the endoscopic approach can be considered as a better alternative.

Keywords: Deviated nasal septum; Endoscopic septoplasty; Conventional septoplasty

\section{Introduction}

Nasal obstruction is one of the most common complain that an otolaryngologist faces on day to day practice [1]. Deviated nasal septum is the most common problem behind this. It not only causes breathing difficulty but also causes impaired aeration to the

paranasal sinus's causes' recurrent infection to the paranasal sinuses [1]. Various techniques have been proposed for the correction of the different types of septal deviations in the past. The concept of submucosal resection was popularized and refined by Killian [2] 
and Freer [3] separately in the early twenties. Later Septoplasty was introduced with less and required excision of deviated portion only, where the surgery is to be done with the help of headlight, but it is a selfish surgery where the assistant can't see the field and the structures to be resected [4]. In this traditional septal surgery, there is often over exposure, unnecessary manipulation of the septal anatomy by a large incision and by elevation of flaps on both sides of nasal septum [5].The advent of endoscope has revolutionized rhinology and has widened the horizon of rhinology. Lanza et al and Stammberger initially described the application of endoscopic technique for the correction of septal deformity in $1991[4,6]$. Furthermore in complex deformities, better correction is possible with the help of an endoscope since we can see the posterior deviation clearly. Endoscope also aided limited resection and thus more conservation by guiding precise shaving of septal cartilage [4].

\section{Materials and Method}

\section{Study design}

A simple random cross-sectional interventional study.

\section{Place of study}

Bangladesh Medical college Hospital, Dhanmondi, Dhaka.

\section{Duration of study}

Jan 2016 to July 2016 (6 months)

\section{Sample size \& Sampling method}

A total 60 patients of symptomatic Deviated Nasal Septum (DNS) within the study period from Jan 2016 to July 2016 were randomly selected. After taking an informed written consent all the selected patients were evaluated with detailed history, clinical examination and proper investigations. All patients were operated

under general anesthesia. Post operatively all patients were packed with antibiotic mixed conventional ribbon pack, that was removed on 2nd POD on conventional septoplasty group and 1st POD on endoscopic septoplasty group. Data were recorded and complied in a structured data sheet and data were analyzed.

\section{Selection criteria}

Inclusion criteria: Patients with symptomatic deviated nasal septum/ septal spur, refractory to conservative treatment.

\section{Exclusion criteria:}

a) Any malignant condition of nose \& paranasal sinuses.

b) Acute infection of nose \& paranasal sinus disease.

c) Diagnosed cases of Sino-nasal polyposis.

\section{Data analysis}

All data were analyzed and presented as both qualitative and quantitative data as applicable using SPSS (Statistical packages for social science) software.

\section{Results}

In the group of conventional septoplasty (CS), youngest patient was of 16 year and the oldest was 52-year-old. Among them most common age group was 21-30, total 14 (46.67\%). In endoscopic septoplasty (ES) group the youngest patient was of 17 year and the oldest was 60-year-old and common age group was 21-30 years. In this study, the male was more common than female with a ratio of 1.86:1. Out of 60 patients, 55 patients $(91.67 \%)$ had presented with nasal obstruction. The next common symptom was headache in 48 patients (80\%). and postnasal drip was in 13 patients $(21.67 \%)$. Least common symptoms were dry mouth, Hyposmia, epistaxis (Table 1).

Table 1: Symptomatology $(n=60)$.

\begin{tabular}{|c|c|c|c|c|}
\hline Complains & ES group (n=30) & Percentage\% & CS group (n=30) & Percentage $\%$ \\
\hline Nasal obstruction & 28 & 93.33 & 27 & 90 \\
\hline Headache & 13 & 43.33 & 10 & 13.33 \\
\hline Snoring & 4 & 13.33 & 7 & 23.33 \\
\hline Dry mouth & 5 & 16.67 & 7 & 3.33 \\
\hline Nasal bleeding & 2 & 6.67 & 3 & 10 \\
\hline Reduced smell sense & 2 & 6.67 & 5 & 16.67 \\
\hline Postnasal drip & 8 & 26.67 & 5 & \\
\hline
\end{tabular}

Isolated DNS was the most common finding, 28 (46.67\%). The next common was DNS with Hypertrophied inferior turbinate (HIT) 19/60 (31.67\%), Septal Spur found in 13/60 (21.67\%) cases. In ES group of patients some additional surgeries was carried out as the associated pathology was visible due to the light of endoscope. Along with septoplasty Functional Endoscopic Sinus Surgery was carried out in 4 patients, submucosal diathermy done in 7 cases $(23.33 \%)$, other commonly performed procedure was ES with conchostomy,
ES with turbinoplasty etc. In CS group only septoplasty was done in 20 patients $(66.67 \%)$ and septoplasty with submucosal diathermy was done in $10 / 30(33.33 \%)$ patients (Table 2 ).

All patients from ES group were discharged on 1st POD, but in conventional group 25 patients (93.3\%) were discharged on 2 nd POD and 2 patients (6.67\%) on 3rd POD. ANS pack was kept in all patients, in ES group pack removed on 1st POD and in most cases of CS pack removed after 48 hours. Nasal splint was kept in all of 
the cases. That was removed on 7th POD. Immediate complication (unusual primary haemorrhage) happened in 1 patient (3.33\%) from ES group while it happened in 6 cases (20\%) in CS group (flap tear in 4, septal perforation in 2) and delayed complication (Synechiae) in $2 / 30(6.66 \%)$ cases of CS group. There was no long-term complication in ES group, but it was 12.27\% 4/30 (2 synechiae, 2 septal perforation) in CS group though the septal perforation cases was repaired after 6 months by the same surgeon.

Post operatively all the patients were followed up on $7^{\text {th }}, 30^{\text {th }}$ day, then at $3^{\text {rd }}$ and $6^{\text {th }}$ month. During each visit the patients were asked about the benefit of the surgery and it was tabulated. During each visit, all patients were examined with $0^{\circ}$ naso-endoscope. Out of 60 patients with nasal obstruction $28 / 30$ patients (93.3\%) from ES group and 25/30 (83.33\%) from CS group were relieved of symptom. Concha bullosa in 2 patients $(6.67 \%)$ and Posterior bony spur in 2 patients $(6.67 \%)$ in CS group was found during endoscopic assessment. Patient's satisfaction was $93.3 \%$ in endoscopic septoplasty and $76.67 \%$ in conventional group.

\section{Discussion}

Nasal obstruction due to DNS is a common problem encountered by otolaryngologist [1]. To relieve this nasal obstruction septoplasty is the commonly performed surgical procedure [7]. In traditional head light based septal surgery there is poor illumination and less accessibility to posterior septum leads to over exposure, unnecessary manipulation of septal anatomy and more resection [5]. The advent of endoscope has revolutionized rhinology and has widened the horizon of rhinology [8]. The nasal endoscope allows precise preoperative identification of the septal pathology and its associated lateral nasal wall abnormalities and helps in better planning of endoscopic aided septal surgery [7]. Endoscopic septoplasty is a directed septoplasty and an effective technique that can be performed safely alone or in combination with endoscopic sinus surgery/endoscopic DCR etc. [8]. This procedure provides very good Illumination and easy approach to posterior bony spur and an excellent teaching tool $[4,8]$. Till date several studies have been conducted to establish these ideas and the results of maximum studies are similar.

In several studies $[6,9]$ the most common age group belongs to 2 nd and 3rd decades. In this study, most common belongs to 3rd decade, that is in concordance with above studies. Krisna, et al. [9] reported a male preponderance in the comparative study of conventional versus endoscopic septoplasty [9], that is in concurrence with our study, where there is a male female ratio of 1.86:1.There are many studies [6,10], where nasal obstruction is the most common complain followed by headache, post nasal drip, dryness of mouth, epistaxis, hyposmia etc. In our study of 60 cases, 55 patients $(91.67 \%)$ had presented with nasal obstruction. The next common symptom was headache in 48 patients (80\%), dryness of mouth was present in 12 patients (40\%), Hyposmia was present in 5 patients $(16.67 \%)$ (Table 1). These are consistent to above mentioned studies.

Nayak, et al. [11] reported that several lateral nasal wall pathologies are associated with deviated nasal septum, the commonest and almost consistent being the inferior turbinate hypertrophy, followed by concha bullosa, paradoxical Middle turbinate, polypoidal middle and inferior turbinate [11]. In the present study we found almost similar findings, commonest being inferior turbinate hypertrophy (41.67\%) followed by septal spur $(33.33 \%)$ (Table 2), that is nearly similar with the study of Mirza, et al. and Nayak, et al. [8,11]. Mahlon, et al. [12] in a retrospective review of 100 patients observed that Endoscopic Septoplasty was performed in 81 patients (81\%), FESS was performed in 43 (43\%) patients, bilateral inferior turbinoplasty in 15 (15\%) patients, partial middle turbinoplasty in $20(20 \%)$ patients. Leena jain, et al. [13] mentioned on the comparative study of conventional and endoscopic Septoplasty, that out of 50 endoscopic Septoplasty, 20 $(40 \%)$ underwent this in conjunction with FESS. In our study among endoscopic septoplasty group, along with septoplasty functional endoscopic sinus surgery was carried out in 4 patients(13.33\%) to clear the pathology (in our series number of FESS was low in number as we intentionally did not advised any patient for computed tomography, so associates sinus pathology if not found preoperatively FESS was not done) partial inferior turbinectomy in 2 patients (6.67\%), turbinoplasty was done in 4 cases (13.33\%) other surgical procedures are ES with Conchostomy, ES with SMD (Table 2). That is comparable to the study of Mirza Aneesa, et al. Mahlon, et al. and Leena J et al $[10,12,13]$.In our study, post operatively ANS pack given in all patients that was removed on 1st POD in ES group but 2nd POD in CS group. All patients from endoscopic septoplasty group were discharged on 1st POD but in conventional group 25 patients (93.3\%) were discharged on 2nd POD. So, it concludes that, there is less hospital stay in endoscopic group in comparison to conventional group. My study is in concurrence with the study of krisna K T [9] and Gupta M [5].

Table 2: Types of Surgical Intervention $(n=60)$.

\begin{tabular}{|c|c|c|c|c|c|}
\hline ES Group & No of Cases (n=30) & Percentage\% & CS group & No of Cases (n=30) & Percentage \% \\
\hline Endoscopic septoplasty (ES) & 10 & 33.3 & Septoplasty & 20 & 66.66 \\
\hline ES with FESS & 4 & 13.3 & Septoplasty with SMD10 & 10 & 33.33 \\
\hline ES with Partial inferior turbinectomy & 2 & 6.67 & & & \\
\hline ES with conchostomy & 3 & 10 & & & \\
\hline ES with turbinoplasty & 4 & 13.3 & & & \\
\hline ES with SMD & 7 & 23.33 & & & \\
\hline
\end{tabular}


Magdy A and Salma, et al. [7] noted that there is significant postoperative symptomatic improvement in ES group compared to CS group. In our 6 months follow up, out of 60 patients with nasal obstruction, 28/30 (93.3\%) belonged to ES and 23/30 patients (76.67\%) belonged to CS group was symptom free. Headache persisted in 2 patients in CS group \& 1 patient in the endoscopic Septoplasty group. Postnasal drip with headache was present in 2 patients of conventional Septoplasty group. Nasal obstruction persisted in 2 patients of conventional group while it is 0 in endoscopic group. Hyposmia was relieved in patients belonging to endoscopic Septoplasty group. Epistaxis was relived in patients belonging to both groups. Our findings are Comparable with the above study. There was significant postoperative improvement in endoscopic septoplasty groups when compared with conventional

Table 3: Post-operative Symptomatology after 6 months.

\begin{tabular}{|c|c|c|}
\hline Symptoms & ES Group & CS Group \\
\hline Nasal blockage & 0 & 2 \\
\hline Headache & 1 & 2 \\
\hline Postnasal drip & 0 & 1 \\
\hline Snoring & 1 & 0 \\
\hline Epistaxis & 0 & 0 \\
\hline
\end{tabular}

Table 4: Complications.

\begin{tabular}{|c|c|c|c|c|}
\hline \multirow{2}{*}{ Complications } & \multicolumn{2}{|c|}{ Endoscopic septoplasty } & \multicolumn{2}{|c|}{ conventional septoplasty } \\
\hline & Immediate & late & Immediate & Late \\
\hline Excessive haemorrhage & 0 & 0 & 2 & 0 \\
\hline Septal perforation & 0 & 0 & 2 & 2 \\
\hline Synechiae & 0 & 0 & 0 & 2 \\
\hline External deformity & 0 & 0 & 0 & 0 \\
\hline Haematoma & 0 & 0 & 0 & 0 \\
\hline Flap tear & 1 & & 4 & \\
\hline
\end{tabular}

In the study of Sandeep K, Siddhart V [16] noticed, 2 out of $30(6.67 \%)$ patient had residual deviation in conventional group but none in endoscopic group. There was no posterior deviation in endoscopic group but it was 1 in 30 (3.33\%) in conventional group, they found septal perforation in $2(6.67 \%)$ patients out of 30 .They observed mucosal tear in $3(10 \%)$ patients in conventional group and $2(6.67 \%)$ in endoscopic group. In our study synechiea was in $2(6.67 \%)$ cases of conventional group and 0 in ES group. 1 patient $(3.33 \%)$ had unilateral flap tear in endoscopic group while

Table 5: Endoscopic versus conventional septoplasty.

\begin{tabular}{|c|c|c|}
\hline & Endoscopic septoplasty & Conventional septoplasty \\
\hline Illumination & excellent & relatively poor \\
\hline Exposure & limited & wide \\
\hline Chance of excessive tissue injury & less & more \\
\hline Posterior bony spur & can be seen easily & can't be seen \\
\hline Flap tear & less & More \\
\hline Septal perforation & Less & More \\
\hline
\end{tabular}

$4(12.33 \%)$ in conventional groups. In our study, 2 patients $(6.67 \%)$ in conventional septoplasty group had extensive intraoperative haemorrhage and no patient in the endoscopic septoplasty group had this. Septal perforation occurred in 2 patients $(6.67 \%)$ belonging to conventional septoplasty group and no patients belonging to endoscopic septoplasty group 2 patients $(6.67 \%)$ belonging to conventional septoplasty had synechiae formation in between septum and inferior turbinate (Table 5). that is comparable to the study of Park DH, et al. [17] and R Bothra, et al. [18]. group (Table 3). That is comparable to many studies $[7,6,14]$.

DC Sathyaki, et al. [1] mentioned in his comparative study, that they examined all patients by $0^{\circ}$ endoscope during post-operative follow-up and noted no persistent deviation or spur in both groups. Persistence of hypertrophy of turbinates on 3 patients out of 11 in conventional group and 1 in 12 of endoscopic group1.In our study there was persistent deformity and posterior bony spur in 3 patients in conventional group and 0 in endoscopic group. There were persistent hypertrophied turbinates (both inferior and middle) in 4 patients in conventional group and 0 in endoscopic group (Table 4). These features are nearly similar to above mentioned study. It also shows some similarity to the literature review done by $\mathrm{C}$ Champagne, et al. [15]. 


\begin{tabular}{|c|c|c|}
\hline Synechiae & Less & More \\
\hline Recurrence of symptoms & less & good \\
\hline Teaching tool & excellent & inexpensive \\
\hline Instruments & costly & more \\
\hline Hospital stay & less & less \\
\hline Patients satisfaction & more & \\
\hline
\end{tabular}

Park DH, et al. [17] conducted a study on 44 patients to compare the endoscopic assisted correction of deviated nose with that of classical septorhinoplasty. Of the 44 patients 16 underwent endoscopic assisted septoplasty and the rest underwent classical septorhinoplasty. The patient satisfaction was $87.5 \%$ and $71.4 \%$ and complications were 0 and $14.3 \%$ for endoscopic and classical approaches respectively [17]. Another study was conducted by Dipak Ranjan Nayak et al. on 60 patients. Among them 30 patients underwent endoscopic assisted septoplasty and rest underwent conventional septoplasty. There was significant improvement of symptoms in patients who underwent endoscopic assisted septoplasty and the objective assessment by nasal endoscopy also showed better results in patients who underwent the same9.. In our study patient's satisfaction was $93.3 \% \& 76.67 \%$ in endoscopic and conventional septoplasty group and complication rate was $3.33 \%$ \& $16.6 \%$ in endoscopic and conventional septoplasty. That is comparable to the study of Park DH, et al. [17] and Dipak RN, et al. [11].

Several authors mentioned in their studies that endoscopic septoplasty is more advantageous than conventional septoplasty in regarding illumination, unnecessary tissue handling, flap tear, septal perforation etc. $[9,14,18]$. Throughout our study we also found that, endoscopic septoplasty allows limited incision and elevation of the flaps that allows adequate exposure of the pathological site. Due to limited extent of flap dissection along with limited manipulation and resection of septal framework, it reduces the chance of adhesion formation. There is less flap tear in comparison with conventional group. The most important thing in endoscopic septoplasty is, as it done under direct visualization on monitor, it played important rule to improve the learning curve of the trainees commented by many authors in their studies $[4,8]$. At the end of our study we also feel that it can play an important rule to improve the learning curve and surgical skill of the trainees significantly $[19,20]$.

\section{Conclusion}

Evolution of the use of endoscope in septoplasty is a major event in the history of septal surgery. It helps in dealing with posterior deviations, high deviations, Sinus pathology, DCR operation, isolated spurs, etc. on the same setting. So, a full house nasal surgery can be done with the aid of endoscope if required. Our study concludes that, it is easier to correct posterior deviation, high deviation and isolated spurs with endoscopic septoplasty, and can improve the learning curve of the trainees significantly which can't be properly done during conventional septoplasty.

\section{Acknowledgement}

None.

\section{Conflict of Interest}

None.

\section{References}

1) DC Sathyki, Chyre Geetha, GB Munishwara, M Mohan (2014) A comparative study of endoscopic septoplasty versus Conventional septoplasty. Indian j of otolaryngology \& head neck surg 66(2): 155161.

2) Killian G (1904) The submucose window resection of the nasal septum. Archives for Laryngology and Rhinology 16: 362.

3) Freer $O$ (1902) The correction of deflections of the nasal septum with a minimum of traumation. J of the American Medical Association 38: 636.

4) Gupta N (2005) Endoscopic septoplasty. Indian j otolaryngology and head neck surgery 57(3): 240-243.

5) M Gupta, G Motwani (2005) Comparative study of endoscopic aided septoplasty and traditional Septoplasty in posterior nasal septal deviations. Indian j of otolaryngology \& head neck surg 57(4): 309311.

6) Manjunath R, Chitradurga SV (2013) Is Endoscopic Septoplasty really superior than Conventional Septoplasty? National journal of otolaryngology and head neck surgery 1(10): 2 .

7) Magdy A, Salma (2014) Endoscopic Aided Septoplasty Versus conventionall Septoplasty. World J of medical science 11(1): 33-38.

8) Mirza AA B, Sajad MQ Irfan I (2015) Endoscopic Septoplasty: A Prospsective Analysis. Open Science journal of clinical medicine 3(6): 212-219.

9) Krishna KT, Bhanu M, Krishnaveni A, Raghunath B, Jeevan Pk (2016) Correction of Deviated Nasal Septum: Conventional Vs Endoscopic Septoplasty. IOSR Journal of Dental and Medical Sciences 13: 14-15.

10) SS Suligavi, MK Darade, BD Guttigoli (2010) Endoscopic septoplasty; Advantage and Disadvantages, Clinical Rhinology. An international journal 3(1): 27-30.

11) Nayak DR, Balakrishnan R, Murthy KD (1998) An endoscopic approach to the deviated nasal septum-a preliminary study. J Laryngol Otol 112 934-939.

12) Mahlon R, Ven D, Paul R, Willeum ED (1999) Endoscopic partial inferior turbinoplasty. Otolaryngology Head and Neck Surgery 121(4): 406-409.

13) Leena J, Manish J, Chauhan A N (2011) Conventional Septoplasty versus endoscopic Septoplasty: A comparative study. People J of scientific Research 4(2): 24-28.

14) Tariq Ashor (2010) Endoscopic Septoplasty Versus Traditional Septoplasty. Journal of the Bahrain Medical society 22(2).

15) C Champagne, S Ballivet de Régloix, L Genestier, A Crambert, O Maurin, et al. (2016) Endoscopic vs conventional septoplasty: A review of the literature. European Annals of Otorhinolaryngology, Head and Neck diseases 133(1): 43-46. 
16) Sandeep Kaushik, Siddhart Vashistha, Nitin Kumar jain (2016) Endoscopic Vs Conventional septoplasty 10013-101159.

17) Park DH, Kim TM, Han DG, Ahn KY (1998) Endoscopic-assisted correction of deviated nose. Aesthetic Plast Surg 22: 190-195.

18) Bothra R, Mathur NN (2009) Comparative evaluation of conventional versus endoscopic septoplasty for limited septal deviation and spur. J Laryngol Otol 123: 737-741.
19) Adriaan F Van Olphen (2010) The Septum (7 ${ }^{\text {th }}$ Edn,) Scott Brown's otolaryngology and Head Neck Surgery 123: 1570

20) H Stammberger, Valerie J Lund (2003) Anatomy of the nose and paranasal sinuses ( $7^{\text {th }}$ Edn,) Scott Brown's otolaryngology and Head Neck Surgery 104: 1327. 